\title{
Identification of HNPCC by molecular analysis of colorectal and endometrial tumors
}

\author{
H.F.A. Vasen ${ }^{\mathrm{a}, \mathrm{b}, *}$, Y. Hendriks ${ }^{\mathrm{c}}$, A.E. de Jong ${ }^{\mathrm{a}, \mathrm{b}}$, M. van Puijenbroek ${ }^{\mathrm{d}}$, C. Tops $^{\mathrm{c}}$, \\ A.H.J.T. Bröcker-Vriends ${ }^{\mathrm{c}}$, J.Th. Wijnen ${ }^{\mathrm{c}}$ and H. Morreau ${ }^{\mathrm{d}}$ \\ ${ }^{a}$ Department of Gastroenterology, Leiden University Medical Centre, Leiden, the Netherlands \\ ${ }^{\mathrm{b}}$ The Netherlands Foundation for the Detection of Hereditary Tumours, Leiden, The Netherlands \\ ${ }^{\mathrm{c}}$ Department of Human and Clinical Genetics, Leiden University Medical Centre, The Netherlands \\ ${ }^{\mathrm{d}}$ Department of Pathology, Leiden University Medical Centre, Leiden, The Netherlands
}

\begin{abstract}
Hereditary nonpolyposis colorectal cancer (HNPCC, Lynch syndrome) is a dominantly inherited syndrome characterized by the development of colorectal cancer, endometrial cancer and other cancers and the presence of microsatellite instability (MSI) in tumors. The Bethesda guidelines have been proposed for the identification of families suspected of HNPCC that require further molecular analysis. We have evaluated the yield of MSI-analysis in a large series of Dutch families suspected of HNPCC. We also analysed whether the loss of mismatch repair (MMR) protein detected by immunohistochemistry (IHC) of colorectal cancer (CRC) and endometrial cancer correlated with the presence of MSI and/or a MMR gene mutation.

The results showed that the Bethesda criteria with a few modifications are appropriate to identify families eligible for genetic testing. In addition, we found that MSI and IHC-analysis of CRC using antibodies against MLH1, MSH2, MSH6 and PMS2 proteins are equally effective for identifying carriers of the known MMR gene defects. However, as long as the role of other putative MMR genes in hereditary CRC has not been elucidated, IHC-analysis cannot completely replace MSI. For this reason, we prefer MSI-analysis as first step in families suspected of HNPCC. On the other hand, in families fulfilling the revised Amsterdam criteria in which the probability of detecting a mutation is relatively high, we would recommend IHC as first diagnostic step because the result might predict the specific underlying MMR gene mutation. MSI or IHC-analysis of endometrial cancer alone was found to be less sensitive compared with these tests performed in colorectal cancer. Therefore, probably the best approach in the analysis of this cancer is to perform both techniques.

The identification of HNPCC is important as it makes it possible to target effective preventative measures. Our studies showed that MSI and IHC analysis of colorectal and endometrial cancer, are reliable cost-effective tools that can be used to identify patients with HNPCC.
\end{abstract}

\section{Introduction}

Approximately $10-15 \%$ of patients with colorectal cancer (CRC) have a family history of CRC, and $5 \%$ of patients have early-onset ( $<45 \mathrm{yrs})$ CRC [1]. In the etiology of CRC in these cases, a combination of genetic and environmental factors is likely to play a

*Corresponding author: H.F.A.Vasen, MD, The Netherlands Foundation for the Detection of Hereditary Tumours, Leiden University Medical Centre (Poortgebouw), Rijnsburgerweg 10, 2333 AA Leiden, The Netherlands. Tel.: +31 71526 2687; Fax: +31 71521 2137; E-mail: nfdht@xs4all.nl. role. In a small fraction of cases, genetic factors play a dominant role. The most common dominantly inherited colorectal cancer syndrome is hereditary nonpolyposis colorectal cancer (HNPCC, Lynch syndrome, hereditary colorectal-endometrial cancer syndrome), which is characterized by the development of colorectal, endometrial, and various other cancers at an early age [2]. This syndrome is due to a mutation in one of the following DNA mismatch repair (MMR) genes: $M S H 2$, $M L H 1, M S H 6$, and PMS2. HNPCC accounts for 1-5\% of all cases of CRC [3].

The identification of individuals predisposed to CRC is important, as it makes it possible to target effec- 
tive preventative measures. A detailed family history is the simplest and most cost-effective way to identify hereditary CRC. As cancer is a common disease, the occurrence of CRC in several members of one family might be due to clustering by chance. Characteristics of hereditary forms of nonpolyposis CRC that might be helpful in the differential diagnosis from nonhereditary cases are an unusual early age of onset, the occurrence of multiple CRCs, and the combined occurrence of CRC with endometrial cancer or another HNPCC associated cancer (in an individual or family).

During the last decade great progress has been made in molecular genetics. Various genes responsible for the inherited forms of CRC have been identified, and genetic testing has been implemented in clinical practice on a large scale. Advantages of genetic testing are that the hereditary nature of the disease can be confirmed, and that, in families with an identified mutation, the carriers of a mutated gene can be differentiated from non-carriers. The latter can be reassured and refrain from further screening. Along with the development of techniques to identify mutated genes, new diagnostic tools such as microsatellite instability (MSI) analysis and immunohistochemistry (IHC) have also been introduced. These new tests have been proven to be useful to select patients suspected of HNPCC for MMR mutation analysis. This review addresses the question how clinical criteria and molecular pathology can be helpful in the diagnosis of HNPCC.

\section{The importance of clinical criteria for HNPCC}

Predisposed individuals from HNPCC families have a high lifetime risk of developing CRC (60-85\%), endometrial cancer (30-50\%), as well as certain other cancers (below 15\%) [4-6]. CRC is often diagnosed at an early age (mean 45 years), can be multiple (with synchronous or metachronous CRC present in $30 \%$ of patients), and, in about two-thirds of the cases is located in the proximal part of the colon. Microscopic features frequently observed in colorectal cancer associated with HNPCC are the presence of peritumoral and tumor infiltrating lymfocytes [7]. Extracolonic cancers observed in HNPCC include cancer of the endometrium, renal pelvis/ureter, stomach, small bowel, ovary, brain, hepatobiliary tract and sebaceous tumors.

The diagnosis of HNPCC is hampered by the absence of specific diagnostic clinical features. Therefore, in 1990, the international collaborative group on HNPCC (ICG-HNPCC) proposed a set of clinical diagnostic cri- teria (the Amsterdam criteria) in order to provide a basis for collaborative studies and to provide uniformity in the terminology of HNPCC [8]. Since then, many studies have shown that HNPCC is also associated with several other extracolonic cancers. That was the reason to propose a new set of criteria (the Amsterdam criteria II) (Table 1), which include various extracolonic cancers [9]. It should be noted that the proposed criteria were not intended for use as exclusion criteria, in other words, families initially suspected of HNPCC but not meeting the criteria should not be falsely reassured and excluded from genetic counselling, genetic testing or surveillance. On the other hand although in most families that meet the Amsterdam criteria there is evidence for a MMR defect, in some families such features (MSI and loss of MMR protein expression) are lacking. In these families, which are generally characterized by a relatively high mean age of onset of CRC and the absence of endometrial cancer, we are probably not dealing with HNPCC and it is questionable whether the HNPCC guidelines for surveillance (e.g. surveillance of endometrium) are applicable in such families.

In 1996, at an NCI workshop clinical criteria were proposed for families suspected for HNPCC that require further molecular analysis (Table 1) [10].

\section{Results of mutation analysis of families suspected of HNPCC}

The identification of the gene defects that are responsible for HNPCC almost ten years ago allowed making a presymptomatic diagnosis. However, due to the heterogeneity of the mutation spectrum in MMR genes, screening for mutations is both time-consuming and expensive. At our centre, mutation analysis has been performed in 287 research families not selected by genetic analysis of the tumour. Mutations were found in $30 \%$ of the families: $13 \%$ harboured a $M S H 2$ mutation, $14 \%$ a $M L H 1$ mutation and $3 \%$ a MSH6 mutation. The mutation detection rates in families meeting the Amsterdam criteria I and those meeting the Amsterdam criteria II were the same $(50 \%)$. In general, in the Netherlands, mutation analysis in families with hereditary cancer is performed if the predicted probability of detecting a mutation is 1 in 10 or higher. This means that the maximum costs of finding one pathogenic mutation is ten times the costs of testing one person (genetic counselling i.e. 1700 Euro and mutation analys is of three genes i.e. $3 \times 620$ Euro) that equals 35.600 Euro. Fortunately, in contrast to other hereditary can- 
Table 1

Clinical criteria for suspected and probable HNPCC

\begin{tabular}{|c|c|}
\hline Suspected HNPCC ${ }^{1}$ & Probable HNPCC ${ }^{2}$ \\
\hline $\begin{array}{l}\text { 1. Patients with multiple synchronous or metachronous HNPCC-related } \\
\text { cancers }^{3}\end{array}$ & $\begin{array}{l}\text { - At least three relatives with CRC, cancer of endometrium, } \\
\text { small bowel, ureter, or renal pelvis }\end{array}$ \\
\hline $\begin{array}{l}\text { 2. Patients with CRC and a first-degree relative with an HNPCC-associated } \\
\text { cancer and/or adenoma, one of them aged }<45 \text { years (adenoma }<40 \text { years) }\end{array}$ & $\begin{array}{l}\text { - One of the three is a first-degree relative of the other two } \\
\text { - At least two consecutive generations affected }\end{array}$ \\
\hline 3. Patients with $\mathrm{CRC}$ or endometrial cancer at age $<45$ years & - Cancer diagnosed at age $<50$ years in at least one relative \\
\hline 4. Patients with adenomas $<40$ years & - Histological confirmation of cancer diagnosis \\
\hline
\end{tabular}

${ }^{1}$ Original Bethesda criteria omitting the Amsterdam criteria.

${ }^{2}$ Amsterdam II criteria.

${ }^{3} \mathrm{CRC}$, endometrial, gastric, hepatobiliary, small-bowel, transitional cell cancer of renal pelvis or ureter.

Table 2

Costs of mutation analysis of MMR genes, MSI and IHC analysis and genetic counselling in the Netherlands

\begin{tabular}{lc}
\hline Type of test & Costs in Euro \\
\hline Mutation analysis three genes & $1860,-$ \\
MSI-analysis & $620,-$ \\
IHC-analysis (four proteins) & $400,-$ \\
Genetic counselling & $1700,-$ \\
\hline
\end{tabular}

cers, in familial CRC cheaper tests, i.e. MSI and IHCanalysis, are available that can be used to identify families which have a high predicted probability of carrying a mutation. The costs of MSI and IHC-analysis, mutation analysis and genetic counselling in the Netherlands are shown in Table 2.

\section{Selection of families for mutation analysis on the basis of micrsatellite instability (MSI) and immunohistochemical analysis (IHC)}

Microsatellite instability (MSI) first reported in 1993 is caused by a failure of the DNA mismatch repair (MMR) system [11-13]. Microsatellites are repetitive DNA sequences found throughout the genome. Loss of MMR function may result in mutations in repetitive coding and noncoding regions of genes including those genes involved in tumor initiation and progression. According to international guidelines for the evaluation of MSI, a panel of five microsatellite markers should be used [10]. If two of the five markers show instability, the tumor is referred to as MSI-high (MSI-H). If one of the markers shows instability the tumor is considered MSI-low (MSI-L). A tumor without any instable marker is designated MS-stable (MSS). If in addition to the recommended set other markers are used, the tumor is referred to as MSI-H when $30 \%$ or more of the markers show instability. If less than $30 \%$ of the markers are unstable the tumor is considered as MSI-L. Because over $90 \%$ of colorectal cancers from patients with HNPCC express a high level of MSI, MSI may aid in the diagnosis of this syndrome [3]. However, MSI is not specific to HNPCC, as it also occurs in $15 \%$ of apparently sporadic colorectal and other tumors. It has been recommended that MSI analysis should be performed in all tumors from patients that belong to families that meet the Bethesda criteria (Table 1) [10].

Another recently introduced rapid and cheap technique to identify mismatch repair deficiency is that of immunohistochemistry (IHC) of the MMR proteins in tumors. Wilson and Leach reported the use of antibodies against the MSH2 protein $[14,15]$. Thibodeau analysed the protein expression of $M L H 1$ and $M S H 2$ in sporadic CRC, familial CRC and CRC associated with HNPCC [16]. Later also the use of antibodies against the MSH6 protein was described.

We have recently evaluated the yield of MSI-analysis in a large series of Dutch families with proven or suspected HNPCC. We also analysed whether loss of MMR protein expression detected by immunohistochemistry correlated with the presence of MSI and/or a MMR germline defect. Here follows a summary of our findings.

\section{Results of MSI-analysis in families that meet the Bethesda criteria}

Various studies have shown that the Bethesda criteria are appropriate to identify HNPCC families [17,18]. We have recently performed MSI-analysis in 725 individuals from 631 families suspected of HNPCC. We used in addition to the five microsatellite markers recommended by the NCI workshop three mononucleotide repeat markers (BAT 40, MSH3 and MSH6) because in our experience these markers, especially BAT 40, increased the sensitivity of the test [19]. Tumors were classified as MSI-H when $>30 \%$ of the markers showed instability, as MSI-L if $<30 \%$ of the markers showed 
instability. We distinguished between MSI-L with instability of a dinucleotide marker only (MSI-Ld) and instability of a mononucleotide marker only (MSI-Lm) because we have found that MSI-Lm is more informative for true MMR deficiency than MSI-Ld. A MSI-H or MSI-Lm phenotype was observed in $39 \%$ of the patients from families that meet the Bethesda criteria [20]. The proportion of MSI-H/MSI-Lm tumors was highest in families that met the Amsterdam criteria (59\%) and in patients with multiple HNPCC associated cancers (44\%). Our database of 631 families included also 195 families that were suspected of HNPCC but that did not fulfill the Bethesda criteria, i.e., families with solitary patients with CRC diagnosed between age 45 and 50 years; families with two first-degree relatives with CRC and HNPCC-cancer, respectively, one diagnosed between age 45 and 50 years; and families with three firstdegree relatives with CRC all diagnosed $>50$ years. Also in these subsets of families a substantial proportion $(>19 \%)$ showed a MSI-H or MSI-Lm phenotype. On the basis of our results we recommend to extend the Bethesda criteria and to perform MSI-analysis also in families that meet the latter criteria.

\section{Comparison of MSI and IHC-analysis}

In order to compare the effectiveness of MSI-analysis and IHC-analysis to identify families with HNPCC, we evaluated the results of these tests in a large series of proven carriers of a pathogenic mutation and in a large series of families suspected of HNPCC [19-21]. In 12 patients with a $M S H 2$ mutation, all colorectal tumors had an MSI-H/L phenotype as well as loss of staining of at least one MMR protein [19]. Analysis of colorectal tumours from 21 MSH6 mutation carriers showed in all cases a MSI-H or MSI-L phenotype. Immunohistochemical analysis of these tumors showed loss of staining of at least one MMR-protein in all but one case [21]. MSI-analysis of tumors from $21 \mathrm{MLH1}$ mutation carriers showed a MSH-H or MSI-L phenotype in $93 \%$ of the cases. However, with IHC-analysis using antibodies against MLH1, MSH2 and MSH6 we missed 3 out of 21 cases [19]. Because the PMS2 protein forms a heterodimer with the MLH1 protein, we hypothesized that absence of the MLH1 protein due to a germline mutation also leads to loss of PMS2 protein caused by abrogation of the total protein complex. Indeed using antibodies against PMS2 in an extended series of tumors from 35 carriers of a MLH1 mutation, loss of both proteins was frequently observed and by adding PMS2 antibodies significantly more (23\%) MLH1 mutation carriers were identified [20]. Data on MSI-analysis as well as IHC staining (4 proteins) were available for 284 tumors of patients from families suspected of HNPCC. Among these 284 tumors, 91 showed MSI-H as well as abnormal staining and 136 tumors showed MSS and normal protein expression, leading to concordant results in $93 \%$ of the MSI-H and MSS tumors. Among tumors with an MSI-L phenotype, those with instability of a mononucleotide marker (MSI-Lm) showed more often absence of an MMR-protein (35\%) than a MSI-L tumor with one instable dinucleotide marker (MSI-Ld) (13\%). In conclusion, MSI and IHC-analysis using antibodies against MLH1, MSH2, PMS2 and MSH6 appear to be equally effective for the identification of mutation carriers.

\section{MSI and IHC- analysis in adenomas from carriers of MMR gene mutation}

According to the Bethesda guidelines, the finding of adenomas in an individual before age 40 years is an indication for MSI-analysis. A large Finnish study of apparently sporadic adenomas have shown that $1.6 \%$ (6/378 adenomas) have a MSI-H phenotype [22]. Five of the six patients with a MSI-H adenoma were found to carry a MMR mutation. Another recent study showed that about $75 \%$ of adenomas detected in HNPCC families showed MSI as well as loss of MMR protein [23]. We recently compared the features of adenomas in a large series of HNPCC mutation carriers and their relatives who were found not to carry a mutated gene (controls) [24]. The adenomas in carriers were larger, and a higher proportion had villous components and/or high grade dysplasia ( $P<0.05$ in all cases). Moreover, in most of the adenomas $(74 \%)$ of the mutation $(\mathrm{MSH} 2$ or $M L H 1$ ) carriers, IHC-analysis showed absence of at least one MMR protein. Based on these findings we recommend IHC-analysis (or MSI-analysis) of adenomas detected in young patients $(<50 \mathrm{yrs})$ if the adenomas are large $(>7 \mathrm{~mm})$, show high-grade dysplasia and/or have a villous component.

\section{MSI and IHC-analysis in endometrial cancer}

Endometrial cancer is the most common extracolonic cancer in women with HNPCC. In some families suspected of HNPCC only tumor tissue is available of endometrial cancer. An important question is therefore 
Table 3

Consequences of test-results on clinical management of families that comply with the Bethesda or Amsterdam criteria

\begin{tabular}{|c|c|c|c|c|}
\hline Clinical criteria & MSI -analysis & IHC-analysis & Mutation analysis & Clinical management \\
\hline Amsterdam criteria & Two MSS tumors & $\begin{array}{l}\text { Normal protein expresssion } \\
\text { in two tumors }\end{array}$ & Not indicated & $\begin{array}{l}\text { Colonoscopy } 1 \mathrm{x} / 3-5 \text { years from } 5-10 \\
\text { years before first diagnosis CRC in } \\
\text { family }\end{array}$ \\
\hline Bethesda criteria $^{1}$ & MSI-H/L & $\begin{array}{l}\text { Loss of MSH2/MSH6 or } \\
\text { MSH6 }\end{array}$ & No mutation identified & According to HNPCC guidelines ${ }^{2}$ \\
\hline Bethesda criteria $^{1}$ & MSI-H/L & Loss of MLH1 & No mutation identified & $\begin{array}{l}\text { According to HNPCC guidelines if ad- } \\
\text { ditional features }{ }^{3} \text { suggest a HNPCC } \\
\text { cancer }\end{array}$ \\
\hline
\end{tabular}

${ }^{1}$ excluding the Amsterdam criteria.

${ }^{2}$ surveillance by colonoscopy every two years from age 20-25 years, annual surveillance of endometrium from age 30 years; consider subtotal colectomy and ileorectal anastomosis in patients that present with CRC.

3 young age, pathology features (tumor heterogeneity, peritumoral lymphocytes, tumor-infiltrating lymphocytes), absence of methylation of MLH1 promotor.

whether MSI and IHC analysis are equally effective to identify HNPCC in endometrial cancer as in CRC. Two recent studies have shown that MSI and loss of MMR protein can be observed in about $35 \%$ of patients with endometrial cancer diagnosed before age 50 years $[25,26]$. In one study, a MMR gene mutation was only identified in endometrial cancer patients who had a first-degree relative with an HNPCC-associated cancer [26]. In the other study, a substantial proportion of patients without a personal or family history of an HNPCC associated cancer had a MSI-H endometrial cancer [25]. In the latter study, no information was provided on the mutation status of the patients.

We have analysed the sensitivity of MSI and IHC in endometrial tumors from family members with a known mutation in $M L H 1, M S H 2$ and MSH6 [27]. We have shown that all endometrial tumors from MLHI/MSH2 mutation carriers demonstrated a MSI-H phenotype, while in endometrial tumors from MSH6 carriers only one third demonstrated a MSI-H phenotype. On the other hand, in tumors from MSH2/MSH6 mutation carriers, IHC predicted the presence of a $M S H 2$ or MSH6 mutation in all cases. However, in tumors from MLH1 mutation carriers, IHC (using antibodies against MLH1, MSH2 and MSH6) could predict the mutation in $M L H 1$ in only $30 \%$ of the cases. Therefore, the best approach in families suspected of HNPCC with only endometrial cancer tissue available for analysis is to perform both MSI-analysis as well as IHC. Future studies should evaluate whether the use of PMS2 antibodies will lead to the identification of more $M L H 1$ mutation carriers. Also more studies are needed to evaluate the value of MSI/IHC- analysis in young $(<50$ years) endometrial cancer patients without a personal and/or family history of an HNPCC-cancer.

\section{Conclusions}

The results of our studies showed that both MSIanalysis as well as IHC-analysis of colorectal tumors is a sensitive screening method to identify patients eligible for mutation analysis. Although our studies indicated that the sensitivity of IHC is approximately the same as that for MSI, IHC cannot completely replace MSI analysis as long as the role of other putative MMR genes in hereditary CRC has not been elucidated. For this reason, we prefer MSI-analysis as first step in families suspected of HNPCC but not fulfilling the Amsterdam criteria. In these cases the probability of detecting a mutation is relatively low $(<25 \%)$. In the total group of Amsterdam-negative families, MSI analysis will provide global information on loss of MMR function, including alterations in MMR genes other than the known genes. In MSI-H and MSI-L cases (if the unstable marker is a mononucleotide), IHC should be performed as second step. In the cases of MSS, IHC for MSH6 might be considered as one study had shown that tumors from MSH6 carriers might be stable (MSS) [28]. On the other hand in families fulfilling the revised Amsterdam criteria in which the probability of detecting a mutation is relatively high $(>50 \%)$, we would recommend IHC as first diagnostic step because the result might indicate which MMR gene is mutated. If a negative staining pattern is found, mutation analysis of the respective gene is the next step. In case of doubtful interpretation or positive staining of all MMR proteins, MSI analysis should be performed. In case of the absence of MSI, the analysis of a second tumor from the same family is recommended to exclude the possibility of phenocopies.

Various studies have shown that MSI and IHC analysis of endometrial cancers are also effective for the 
identification of HNPCC. Our studies indicated that the best approach is to use IHC-analysis as well as MSIanalysis in endometrial cancer from members of families suspected of HNPCC. MSI and IHC analysis should also be performed in young patients with adenomas, which are large $(>7 \mathrm{~mm})$ and/or show high degree of dysplasia and/or a villous component.

An important question is what are the clinical consequences for relatives of patients with tests results (MSI/IHC) suggesting the presence of an MMR gene mutation but without identifying an MMR gene defect. There is no doubt that if a patient from a family that meets the Bethesda criteria has a tumor showing a MSI-H phenotype and loss of MSH2/MSH6 protein, he/she should be considered as HNPCC also if a germline $M S H 2$ or $M S H 6$ mutation cannot be identified. However, a more difficult question is whether a patient from a Bethesda positive family with a MSI-H CRC diagnosed at an intermediate age (50-65 years), loss of staining of MLH1 but without an MLH1 mutation, should also be considered as an HNPCC patient? The question is whether the cancer has occurred sporadically or in the setting of an underlying germ-line mutation (HNPCC). Australian investigators have addressed this issue by examining the histopathological features, molecular changes, alteration in the immunohistochemical profile, methylation, and patient age and sex in a large series of patients with either a sporadic MSI-H CRC or a HNPCC cancer [29]. Although they were not able to separate the two types of cancer into non-overlapping groups, and found that no single assay can be used to unequivocally partition of the groups, the combination of age at diagnosis and three pathology features (tumor heterogeneity, peritumoral lymphocytes, and tumor-infiltrating lymphocytes) allowed most of MSI-H cancers $(>90 \%)$ to be classified as sporadic or HNPCC. If the cancer is classified as HNPCC, then the first-degree relatives should be screened according to the HNPCC guidelines (colonoscopy every two years starting from age 20-25 years) (Table 3).

At present, MSI and IHC-analysis are advised only in families that comply with specific criteria. Because, there is increasing evidence that MSI is an important prognostic factor and may predict the response to chemotherapy, in the near future these tests might be performed on a much larger scale if not in all CRC cases $[30,31]$.

\section{References}

[1] M.L. Slattery and R.A. Kerber, Family history of cancer and colon cancer risk: the Utah Population Database, J Natl Cancer Inst 86(21) (1994), 1618-1626.
[2] H.T. Lynch and C.A. de la, Hereditary colorectal cancer, $N$ Engl J Med 348(10) (2003), 919-932.

[3] L.A. Aaltonen, R. Salovaara, P. Kristo, F. Canzian, A, Hemminki and P. Peltomaki et al., Incidence of hereditary nonpolyposis colorectal cancer and the feasibility of molecular screening for the disease, N Engl J Med 338(21) (1998), 1481-1487.

[4] H.F. Vasen, J.T. Wijnen, F.H. Menko, J.H. Kleibeuker, B.G. Taal and G. Griffioen et al., Cancer risk in families with hereditary nonpolyposis colorectal cancer diagnosed by mutation analysis, Gastroenterology 110(4) (1996), 1020-1027.

[5] M. Aarnio, R. Sankila, E. Pukkala, R. Salovaara, L.A. Aaltonen, C.A. de la et al., Cancer risk in mutation carriers of DNAmismatch-repair genes, Int J Cancer 81(2) (1999), 214-218.

[6] H.F. Vasen, A. Stormorken, F.H. Menko, F.M. Nagengast, J.H. Kleibeuker and G. Griffioen et al., MSH2 mutation carriers are at higher risk of cancer than MLH1 mutation carriers: a study of hereditary nonpolyposis colorectal cancer families, $J$ Clin Oncol 19(20) (2001), 4074-4080.

[7] M. Shashidharan, T. Smyrk, K.M. Lin, C.A. Ternent, A.G. Thorson, G.J. Blatchford et al., Histologic comparison of hereditary nonpolyposis colorectal cancer associated with MSH2 and MLH1 and colorectal cancer from the general population, Dis Colon Rectum 42(6) (1999), 722-726.

[8] H.F. Vasen, J.P. Mecklin, P.M. Khan and H.T. Lynch, The International Collaborative Group on Hereditary Non-Polyposis Colorectal Cancer (ICG-HNPCC), Dis Colon Rectum 34(5) (1991), 424-425.

[9] H.F. Vasen, P. Watson, J.P. Mecklin and H.T. Lynch, New clinical criteria for hereditary nonpolyposis colorectal cancer $(\mathrm{HN}$ PCC, Lynch syndrome) proposed by the International Collaborative group on HNPCC, Gastroenterology 116(6) (1999), 1453-1456.

[10] M.A. Rodriguez-Bigas, C.R. Boland, S.R. Hamilton, D.E. Henson, J.R. Jass and P.M. Khan et al., A National Cancer Institute Workshop on Hereditary Nonpolyposis Colorectal Cancer Syndrome: meeting highlights and Bethesda guidelines, $J$ Natl Cancer Inst 89(23) (1997), 1758-1762.

[11] S.N. Thibodeau, G. Bren and D. Schaid, Microsatellite instability in cancer of the proximal colon, Science 260(5109) (1993), 816-819.

[12] L.A. Aaltonen, P. Peltomaki, F.S. Leach, P. Sistonen, L. Pylkkanen and J.P. Mecklin et al., Clues to the pathogenesis of familial colorectal cancer, Science 260(5109) (1993), 812-816.

[13] Y. Ionov, M.A. Peinado, S. Malkhosyan, D. Shibata and M. Perucho, Ubiquitous somatic mutations in simple repeated sequences reveal a new mechanism for colonic carcinogenesis, Nature 363(6429) (1993), 558-561.

[14] T.M. Wilson, A. Ewel, J.R. Duguid, J.N. Eble, M.K. Lescoe and R. Fishel et al., Differential cellular expression of the human MSH2 repair enzyme in small and large intestine, Cancer Res 55(22) (1995), 5146-5150.

[15] F.S. Leach, K. Polyak, M. Burrell, K.A. Johnson, D. Hill and M.G. Dunlop et al., Expression of the human mismatch repair gene hMSH2 in normal and neoplastic tissues, Cancer Res 56(2) (1996), 235-240.

[16] S.N. Thibodeau, A.J. French, P.C. Roche, J.M. Cunningham, D.J. Tester and N.M. Lindor et al., Altered expression of hMSH2 and hMLH1 in tumors with microsatellite instability and genetic alterations in mismatch repair genes, Cancer Res 56(21) (1996), 4836-4840.

[17] H.P. Wullenweber, C. Sutter, F. Autschbach, F. Willeke, P. Kienle and A. Benner et al., Evaluation of Bethesda guidelines 
in relation to microsatellite instability, Dis Colon Rectum 44(9) (2001), 1281-1289.

[18] J. Plaschke, S. Kruger, S. Pistorius, F. Theissig, H.D. Saeger and H.K. Schackert, Involvement of hMSH6 in the development of hereditary and sporadic colorectal cancer revealed by immunostaining is based on germline mutations, but rarely on somatic inactivation, Int J Cancer 97(5) (2002), 643-648.

[19] Y. Hendriks, P. Franken, J.W. Dierssen, W. De Leeuw, J. Wijnen and E. Dreef et al., Conventional and tissue microarray immunohistochemical expression analysis of mismatch repair in hereditary colorectal tumors, Am J Pathol 162(2) (2003), 469-477.

[20] A.E. De Jong, M. Van Puijenbroek, C. Tops, J. Wijnen, M.G.E.M. Aussems and E.H. Meijers-Heijboer et al., Results of MSI and IHC analysis of a large sereis of Dutch families suspected of HNPCC, Clin Cancer Research (2004), in press.

[21] Y. Hendriks, A. Wagner, H. Morreau, F. Menko, A. Stormorken and F. Quehenberger et al., Cancer risk in hereditary nonpolyposis colorectal cancer associated with MSH6 mutations:consequences for counselling and surveillance, Gastroenterology (2004), in press.

[22] A. Loukola, R. Salovaara, P. Kristo, A.L. Moisio, H. Kaariainen and $\mathrm{H}$. Ahtola et al., Microsatellite instability in adenomas as a marker for hereditary nonpolyposis colorectal cancer, Am J Pathol 155(6) (1999), 1849-1853.

[23] H. Iino, L. Simms, J. Young, J. Arnold, I.M. Winship, S.I. Webb et al., DNA microsatellite instability and mismatch repair protein loss in adenomas presenting in hereditary nonpolyposis colorectal cancer, Gut 47(1) (2000), 37-42.

[24] A.E. De Jong, H. Morreau, M. Van Puijenbroek, P.H. Eilers, J. Wijnen and F.M. Nagengast et al., The role of mismatch repair gene defects in the development of adenomas in patients with HNPCC, Gastroenterology 126(1) (2004), 42-48.

[25] Y.R. Parc, K.C. Halling, L.J. Burgart, S.K. McDonnell, D.G.
Schaid and S.N. Thibodeau et al., Microsatellite instability and $\mathrm{hMLH} 1 / \mathrm{hMSH} 2$ expression in young endometrial carcinoma patients: associations with family history and histopathology, Int J Cancer 86(1) (2000), 60-66.

[26] M.J. Berends, Y. Wu, R.H. Sijmons, S.T. van der, W.B. Ek and M.J. Ligtenberg et al., Toward new strategies to select young endometrial cancer patients for mismatch repair gene mutation analysis, J Clin Oncol 21(23) (2003), 4364-4370.

[27] W.J. de Leeuw, J. Dierssen, H.F. Vasen, J.T. Wijnen, G.G. Kenter and $\mathrm{H}$. Meijers-Heijboer et al., Prediction of a mismatch repair gene defect by microsatellite instability and immunohistochemical analysis in endometrial tumours from HNPCC patients, J Pathol 192(3) (2000), 328-335.

[28] M.J. Berends, Y. Wu, R.H. Sijmons, R.G. Mensink, S.T. van der and J.M. Hordijk-Hos et al., Molecular and clinical characteristics of MSH6 variants: an analysis of 25 index carriers of a germline variant, Am J Hum Genet 70(1) (2002), 26-37.

[29] J. Young, L.A. Simms, K.G. Biden, C. Wynter, V. Whitehall and R. Karamatic et al., Features of colorectal cancers with high-level microsatellite instability occurring in familial and sporadic settings: parallel pathways of tumorigenesis, Am J Pathol 159(6) (2001), 2107-2116.

[30] C.M. Ribic, D.J. Sargent, M.J. Moore, S.N. Thibodeau, A.J. French and R.M. Goldberg et al., Tumor microsatelliteinstability status as a predictor of benefit from fluorouracilbased adjuvant chemotherapy for colon cancer, $N$ Engl $\mathrm{J}$ Med 349(3) (2003), 247-257.

[31] W. de Vos tot Nederveen Cappel, h. Meulebeld, J.H. Kleibeuker, F.M. Nagengast, F.H. Menko, G. Griffioen, A. Cats, H. Morreau, H. Gelderblom and H.F.A. Vasen, Survival after adjuvant 5 -FU treatment for Stage III colon cancer in hereditary non polyposis colorectal cancer, Int J Cancer (2004), in press. 


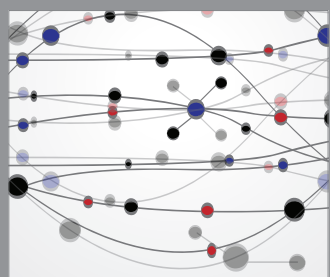

The Scientific World Journal
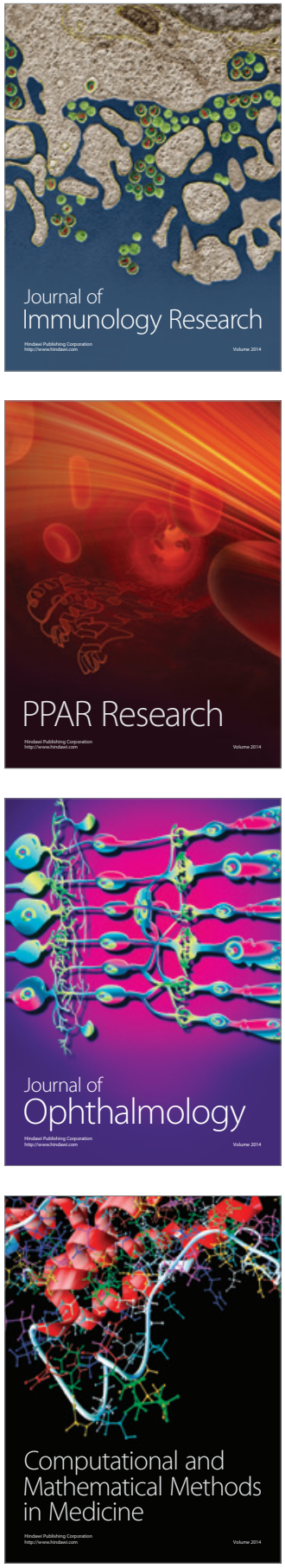

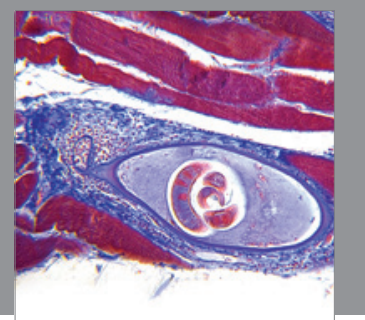

Gastroenterology

Research and Practice
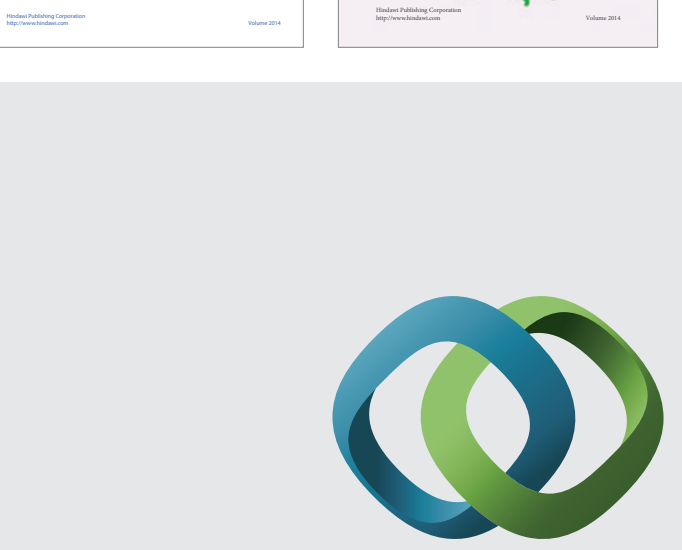

\section{Hindawi}

Submit your manuscripts at

http://www.hindawi.com
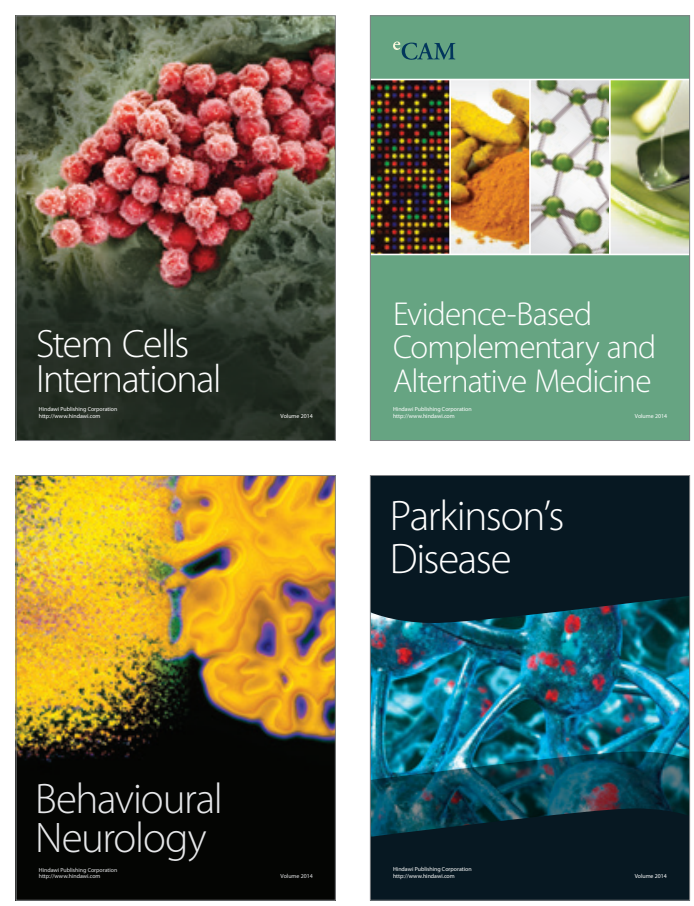

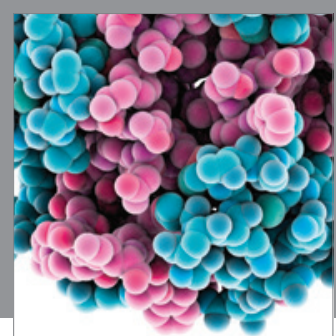

Journal of
Diabetes Research

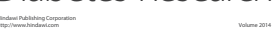

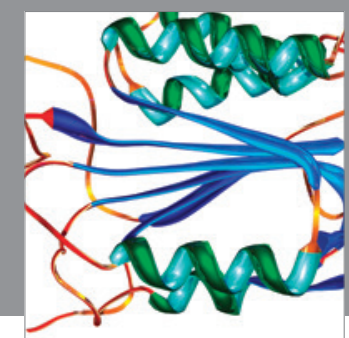

Disease Markers
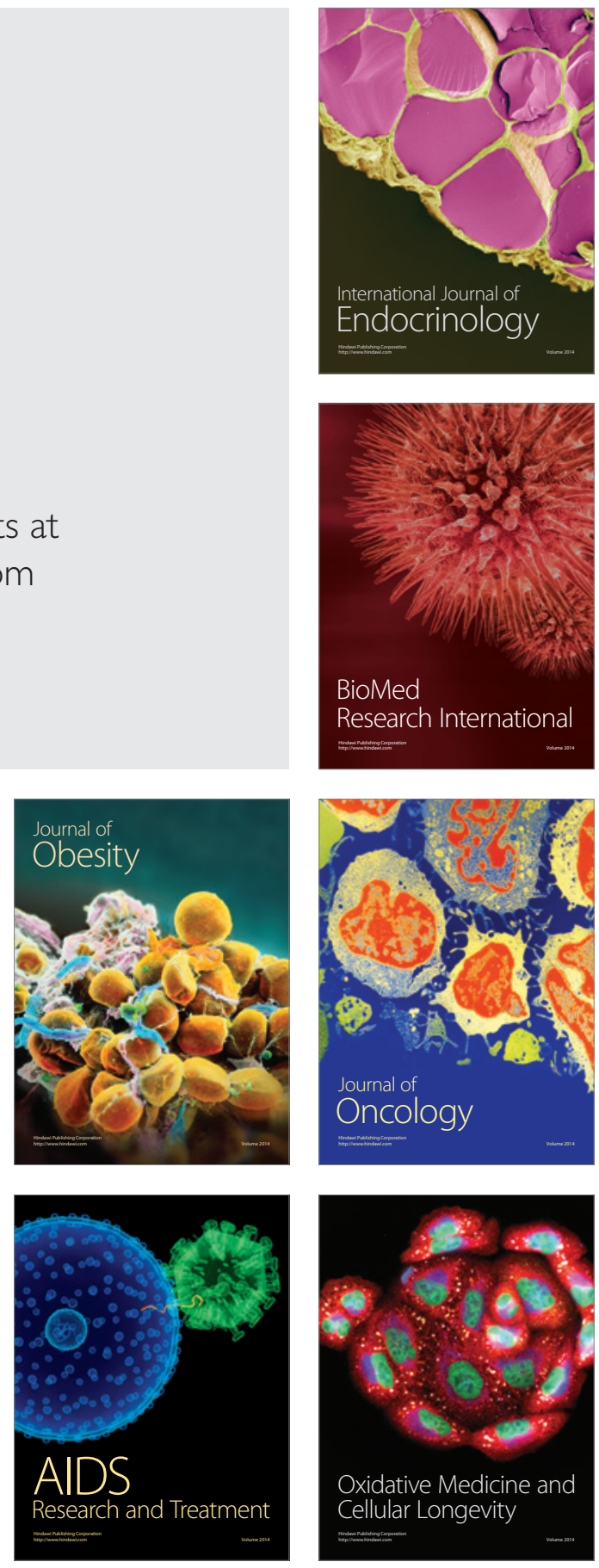